\title{
DEVELOPING DAMAGE TOLERANCE AND CREEP RESISTANCE IN A HIGH STRENGTH NICKEL ALLOY FOR DISC APPLICATIONS
}

\author{
M.C. Hardy ${ }^{1}$, B. Zirbel ${ }^{2}$, G. Shen ${ }^{2}$, and R. Shankar ${ }^{2}$ \\ ${ }^{1}$ Rolls-Royce plc, PO Box 31, Derby, DE24 8BJ, United Kingdom \\ ${ }^{2}$ Ladish Co., Inc., Cudahy, Wisconsin, 53110, USA
}

Keywords: powder metallurgy, RR1000, disc forgings

\begin{abstract}
The development of an affordable nickel disc alloy that shows the required combination of strength, damage tolerance and creep resistance continues to challenge materials engineers. RollsRoyce has developed the alloy known as RR1000, which when processed to produce a fine grain microstructure, shows at least a $25^{\circ} \mathrm{C}$ increase in temperature capability over the current disc alloy, $720 \mathrm{Li}$, and has an equivalent crack growth resistance to coarse grain Waspaloy. This paper discusses the steps that were taken to attain these mechanical properties, and also examines the potential to increase temperature capability by a further $30^{\circ} \mathrm{C}$ through the development of a coarse microstructure in selected areas of disc forgings.
\end{abstract}

\section{Introduction}

To meet the demand for reduced acquisition and life cycle costs in civil aviation, modern gas turbine engines are expected to achieve increasingly higher levels of fuel economy, reduced NOx emissions and noise, and with reduced module weight. These challenges inevitably necessitate higher overall pressure ratios, and higher compressor discharge and turbine entry temperatures. As such, disc rotors in the High Pressure compressor and turbine must accommodate higher temperatures and stresses. This places significant demands on the high strength nickel alloys that are used for these critical components, particularly as loss of integrity can threaten the safety of the aircraft and passengers. If acceptable component lives cannot be achieved using existing alloys, then a new disc alloy will need to be introduced. RollsRoyce has developed the alloy known as RR1000 to replace alloy $720 \mathrm{Li}$, which is the best of the current list of nickel disc alloys that is available to the Company.

\section{Alloy Composition}

Traditionally, alloys have been developed by empirical methods that have involved much iteration and have relied on many years of experience and expertise. These methods have been based on binary or tertiary equilibrium phase diagrams. Although this approach has received some notable successes, it is very time consuming and costly, and may not produce an optimised alloy chemistry. In recent years, Rolls-Royce has chosen to use analytical methods such as phase diagram modelling to assist in the process of alloy chemistry definition.

Advances in thermodynamic modelling have allowed the accurate prediction of complex phase equilibrium in real engineering alloys ${ }^{1}$. Rolls-Royce has developed this methodology for use with nickel based superalloys ${ }^{2}$ and is able to predict accurately, the existence of stable phases at fabrication and operating temperatures (Figure 1$)^{3}$. The use of thermodynamic modelling also enables the alloy designer to predict the outcome of a set of conditions that deviate from equilibrium, as well as fundamental alloy responses, such as anti-phase boundary energies (APB $)^{4}$, that reflect the potential creep behaviour and strength of alloys.

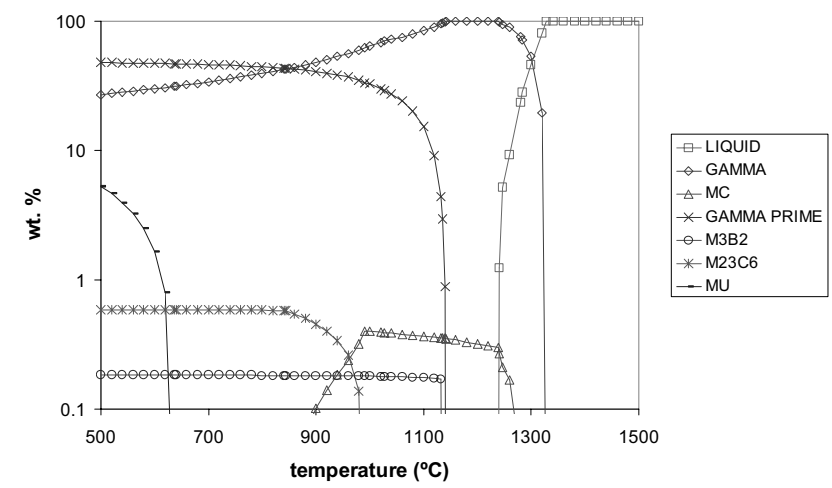

Figure 1. Phase equilibria for RR $1000^{3}$ generated using JMat Pro.

The database established for the calculation of phase equilibria has been used to predict the formation of undesirable topologically closed packed (TCP) phases during prolonged exposure at elevated temperature ${ }^{2}$. In the past, the phase computation (PHACOMP) method $^{5}$ has been used as a guide to avoid the formation of the deleterious $\sigma$ phase. The approach relies on calculating the average electron valency number, Nv, for the alloy and defining an alloy specific number, below which, the alloy is deemed to be ' $\sigma$ safe'. Although this approach has been used extensively, it does not allow for the true complexity of TCP formation to be taken into consideration and ignores other deleterious TCP phases such as $\mu, \chi, \mathrm{P}$ and R. Furthermore, PHACOMP, gives no information on temperature ranges of stability, phase boundaries, segregation effects or potential operating windows. The determination of metastable equilibrium conditions from thermodynamic modelling overcomes most of these limitations. It has thus been used as a starting point for experimental work to characterise the morphology of $\sigma$ in exposed material and to determine the precipitation kinetics of $\sigma$ in development alloys ${ }^{6}$. Whilst the precipitation of $\sigma$, in a particular morphology and in a sufficient concentration, will degrade mechanical properties, coarsening of tertiary $\gamma^{\prime}$ during exposure at elevated temperature may have an equally damaging effect $^{3}$.

The composition of RR1000 (Table I) was defined through the use of thermodynamic modelling and an understanding of the role and 
benefits of elemental additions and interactions on the mechanical properties of superalloys ${ }^{7}$. The influence of the major alloy

constituents on behaviour is discussed in the following text.

TABLE I. Composition of 3 Variants of RR1000 in Weight Percent ${ }^{7}$.

\begin{tabular}{|c|c|c|c|c|c|c|c|c|c|c|c|}
\hline Alloy & Co & Cr & Mo & Ti & Al & Ta & Hf & C & B & $\mathrm{Zr}$ & $\mathrm{Ni}$ \\
\hline$\# 1$ & 18.5 & 15 & 5 & 3.6 & 3 & 2 & 0.75 & 0.03 & 0.02 & 0.06 & Bal. \\
\hline$\# 2$ & 18.5 & 15 & 5 & 3.6 & 3 & 2 & 0.5 & 0.03 & 0.02 & 0.06 & Bal. \\
\hline$\# 3$ & 18.5 & 15 & 5 & 3.6 & 3 & 2 & 0 & 0.03 & 0.02 & 0.06 & Bal. \\
\hline
\end{tabular}

It has been established that strength is derived from solid solution strengthening and $\gamma^{\prime}$ precipitates ${ }^{8,9}$, the degree of strengthening being a function of the size and concentration of solute atoms and the volume fraction and size of $\gamma^{\prime}$ precipitates. The contribution to strength of lattice misfit strain from solute atoms, and the perceived patent restrictions in using tungsten have resulted in high levels of aluminium, molybdenum, chromium and cobalt in RR1000. Principles of alloy design ${ }^{8}$ indicate that a large misfit between coherent $\gamma^{\prime}$ precipitates and $\gamma$ matrix is beneficial for low temperature strength. Conversely, a low misfit is generally preferred for high temperature creep resistance. As disc applications require low temperature strength that is maintained at temperatures in excess of $650^{\circ} \mathrm{C}$, these alloy design principles appear to conflict. In designing RR1000, the objective was to develop a misfit that contributes to strength, but to ensure that $\gamma$ ' remained coherent.

Particular attention was paid to the influence of chemistry on crack growth behaviour as previous nickel disc alloys have struggled to exhibit the required balance between strength and fatigue crack growth resistance. Alloys such as IN100 and Rene 95 , for example, that have volume fractions of $\gamma^{\prime}$ as high as 50-60 $\%$ show high tensile strength but suffer from very fast rates of crack growth. Consequently, in developing RR1000, the aim was to achieve the desired levels of strength at a reduced volume fraction of $\gamma^{\prime}$. This involved manipulating the solute atoms that partition to the $\gamma$, specifically aluminium, titanium and tantalum. In practice, the titanium content was adjusted to reflect the necessary levels of tantalum and aluminium. Whilst tantalum increases strength, it was found to increase crack growth rate and as a result was limited to $2.15 \mathrm{wt} . \%$. Similarly, the aluminium content was restricted to $3.15 \mathrm{wt} . \%$, since additional aluminium would increase the volume fraction of $\gamma^{\prime}$ and lead to chromium enrichment of the $\gamma$ matrix and thereby increase the propensity for TCP phase formation. The titanium content was therefore increased to give a $45 \%$ weight fraction of $\gamma^{\prime}$ at $725^{\circ} \mathrm{C}$.

Encouraging planar slip was also considered to be important if low crack growth rates were to be achieved. In this heterogeneous form of deformation, it is understood that dislocations cut precipitate particles rather than loop around them, as in more homogeneous slip. This is advantageous as reversal of slip during the unloading component of a fatigue cycle is relatively easy compared to slip reversal on more homogeneous, wavy slip paths ${ }^{10}$. As such, there is less damage accumulation. The ability to inhibit cross slip also has a beneficial effect on creep behaviour. Since a low stacking fault energy (SFE) is known to promote planar slip, the cobalt content in the alloy was optimised to produce a minimum value of SFE. In addition, cobalt is considered to reduce the solubility of aluminium and titanium in $\gamma$, which maximises the partition of these elements to the $\gamma^{\prime}$, and to reduce the $\gamma$ ' solvus temperature.

As well as oxidation resistance, chromium was found to reduce the rate of crack propagation at elevated temperature. However, experience has shown that a level of $18 \mathrm{wt} \%$ in alloy 720 causes excessive precipitation of $\sigma$ and $\mu$ phases after relatively short exposure times above $700^{\circ} \mathrm{C}^{2,11}$. Since these phases are known to degrade the creep properties of nickel disc alloys ${ }^{12,13}$, a balance between improved fatigue crack growth resistance and reduced TCP phase formation was struck at around $15 \mathrm{wt} . \%$ chromium. Consequently, chromium is critical in achieving a balance between strength and damage tolerance. This was made possible by imposing a limit on the molybdenum content at the expense of potential gains in high temperature strength and creep resistance. The mechanism for the observed improvement in crack growth rates at elevated temperature is not fully understood. One explanation may lie in the ability to decorate grain boundaries with $\mathrm{M}_{23} \mathrm{C}_{6}(\mathrm{M}=\mathrm{Cr}, \mathrm{Mo})$ and $\mathrm{M}_{6} \mathrm{C}(\mathrm{M}=\mathrm{Mo})$ carbides in order to retain transgranular crack growth. Alloy variants with reduced levels of chromium, below $15 \mathrm{wt} . \%$, were very stable but showed mixed transgranular and intergranular cracking and higher rates of crack growth. It was discovered that these only had $\mathrm{MC}(\mathrm{M}=\mathrm{Ta}$, $\mathrm{Ti}$, Hf if added) carbides at the grain boundaries.

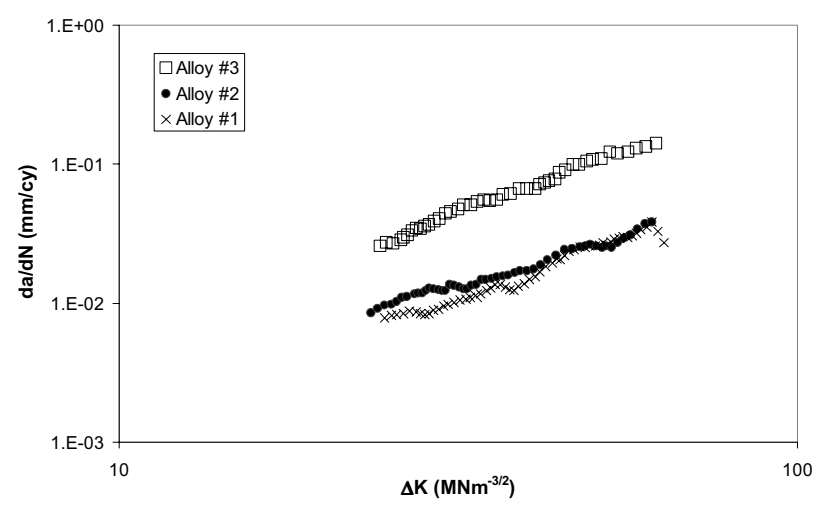

Figure 2. Crack growth rate data at $725^{\circ} \mathrm{C}$ for hafnium bearing and hafnium free RR1000, generated from fatigue cycles that have a $120 \mathrm{~s}$ dwell at maximum load and a stress ratio of $0.1^{14}$. The material showed an average grain size of ASTM 10-9 (11-16 $\mu \mathrm{m})$.

The minimum levels of boron, carbon and zirconium that were required to produce enhanced high temperature properties, notably creep, were added. Boron was also considered to be of benefit to the fatigue performance of the alloy. It was found that the addition of hafnium enabled significant improvements in the crack growth $^{14}$ (Figure 2) and creep resistance of RR1000, and produced moderate increases in tensile strength, since it partitions to $\gamma$. 
Hafnium also forms a primary carbide that remains stable at low temperatures, which is considered to prevent excessive $\mathrm{M}_{23} \mathrm{C}_{6}$ and $\mathrm{M}_{6} \mathrm{C}$ formation at grain boundaries. However, these benefits need to be assessed against the challenges in processing hafniumbearing alloys and in managing the risk of micron-sized hafnia particles, either as small agglomerations or attached to the periphery of other melt anomalies.

Having determined the chemistry of this new alloy, decisions then had to be made concerning the processing route and heat treatment schedule. Both of these steps have a profound effect on the mechanical properties and the material cleanliness of the alloy.

\section{Production of Billet for Large Diameter Disc Forgings}

Although billet for large-scale forgings of alloy $720 \mathrm{Li}$ are being produced via the cast and wrought route ${ }^{15}$, powder metallurgy is being considered for increasingly complex nickel disc alloys, such as RR1000, to avoid the risk of elemental segregation and unacceptable levels of carbonitride stringers. It is recognised that the use of powder processing will increase the price of billet material above the level for cast and wrought $720 \mathrm{Li}$, and requires specific methods for probabilistic design/lifing and for ensuring that a consistent level of cleanliness is maintained in production material. Whilst the powder route is currently preferred, it is considered that large diameter billet can be produced from cast and wrought processing but is unlikely to offer a cost saving over the powder product.

It is well documented ${ }^{16,17}$ that the presence of inclusions, which are picked up during powder processing, can severely limit the fatigue performance of the alloy. Over the last decade, the cleanliness of argon gas atomised powder has improved considerably through the elimination of organic seals and the use of progressively finer sieve sizes to screen out non-metallic inclusions. This has been made affordable by the development of nozzles for high yield powder production ${ }^{18}$. RR1000 powder is now being produced using these nozzles and argon gas atomisation, and is screened to a final sieve size of -270 mesh (53 $\mu \mathrm{m})$.

Following consolidation of canned powder by hot isostatic pressing or hot compaction, it is the industry practice to extrude the cans to a reduction ratio greater than 4.5:1. Nominally 12" diameter RR1000 billet, which is preferred for large turbine discs, is extruded to this specification. The purpose of the extrusion stage is to break down any prior particle boundaries and to produce a fine grain size that is typically smaller than ASTM 12 $(6 \mu \mathrm{m})$. This structure is ideal for inspection of the billet and subsequent superplastic deformation on isothermal forging. Given the limited number of sources for extrusion of large diameter billet, smaller reduction $\operatorname{ratios}^{19}$ and alternative consolidation methods are being evaluated ${ }^{19,}{ }^{20}$. These are particularly attractive for small powder campaigns as they offer cost savings.

\section{Forging and Heat Treatment}

Whilst the hot die route can be used for some forging operations on RR1000, the majority of the necessary hot work required to produce the desired finished shape and grain structure is accomplished by isothermal forging. As lower strain rates are used during deformation, isothermal forging currently offers greater control of structure and the ability to forge quite complex, 'near-net' shapes that enable significant reductions in material input weight and machining time ${ }^{21}$.

As grain size and the size of secondary and tertiary $\gamma^{\prime}$ precipitates determine mechanical properties, forging and solution treatment temperatures, quench rates from solution treatment, and ageing temperature and time need to be considered carefully so that heat treated forgings meet expectation. Strength and resistance to low cycle fatigue have been optimised for disc applications by developing a fine grain size through sub-solvus heat treatment, and by quenching in oil to maximise cooling rates, and thereby, minimise the size of secondary (and tertiary) $\gamma$ '. This approach tends to produce less appealing crack growth resistance. There is some evidence to suggest that fast quenching leaves grain boundary regions free of secondary and tertiary $\gamma$, which increases the propensity for intergranular cracking and very fast rates of crack growth under creep-fatigue conditions ${ }^{22}$. A more homogeneous distribution of these $\gamma$ ' particles and consequently, a significantly superior resistance to elevated crack growth, is produced from slower rates of cooling, such as from air-cooling.

There are other concerns for alloys that have a high volume fraction of $\gamma^{\prime}$. Rapid quenching in oil from solution treatment can cause quench cracking in thin sections or at corners of complex forging shapes. Significant internal residual stresses also develop from cooling rate gradients that can occur in forgings due to differences in section size. These have been found to produce distortion during machining, which increases the time and cost for component manufacture. Residual stresses can be relieved by heat treatment but inevitably at temperatures that are higher than the ageing temperature, which coarsens the tertiary $\gamma^{\prime}$ and leads to a degradation of mechanical properties.

There is added incentive to minimise quenching stresses in powder-processed alloys due to the occurrence of ceramic inclusions. Although the majority of these inclusions are small, they must remain uncracked if the finished component is to realise the full fatigue life potential of the alloy. Evidence from cyclic rig tests on subscale powder $\operatorname{discs}^{23}$ has shown that having considered quenching residual stresses after ageing, discs produced from fan air-cooled forgings exhibit a greater fatigue life than those machined from oil quenched forgings. For this and the other reasons given above, RR1000 forgings have been fan air-cooled after solution treatment. However, as the strength of the alloy is not fully optimised, the design envelope for discs may increase to provide the required tolerance to counter high stresses that may arise from unforeseen shaft over-speed events.

The decision not to oil quench has limited the solution heat treatment of RR1000 to temperatures below the $\gamma^{\prime}$ solvus. This is apparent from Figure 3. It shows that the proof and tensile strength of material that has been taken from a large section of a forging, such as the bore/cob, are considerably reduced if the material has a coarse microstructure. Consequently, work has been directed towards developing a process window for a nearsolvus solution treatment, to produce an average grain size of ASTM 12 to $9(6-16 \mu \mathrm{m})$, which would enable an acceptable balance to be achieved between tensile strength and crack growth resistance. Even within this relatively small range of target grain sizes, it has been found that a significant variation in crack growth 
rate can occur at temperatures and conditions in which oxidation and time dependent deformation result in a mixed transgranular and intergranular crack growth mechanism ${ }^{24}$. Figure 4 illustrates this observation. It shows that a reduction in grain size from ASTM 10-9 (11-16 $\mu \mathrm{m})$ to ASTM 12-11 $(6-8 \mu \mathrm{m})$ has increased the rate of crack growth at $650^{\circ} \mathrm{C}$ beyond expected levels of scatter.

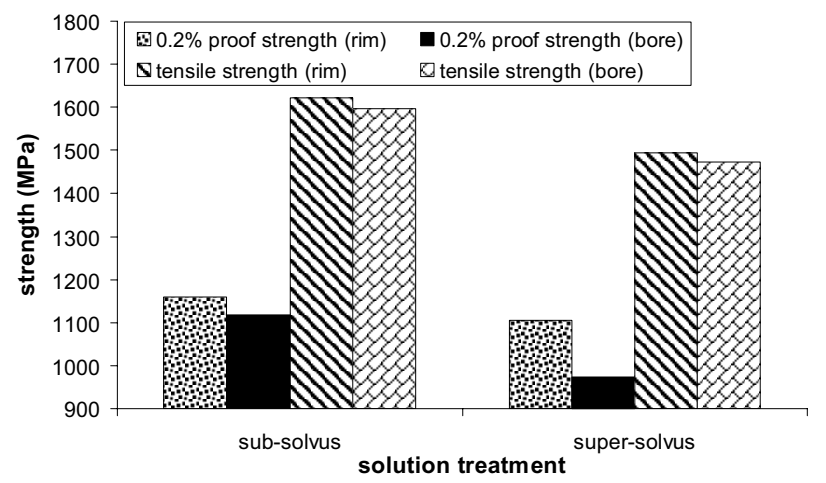

Figure 3. The influence of solution treatment temperature on the room temperature proof and ultimate tensile strength of Alloy \#1 (in the fully heat treated condition). Fan air-cooling was used to quench large-scale forgings after solution treatment.

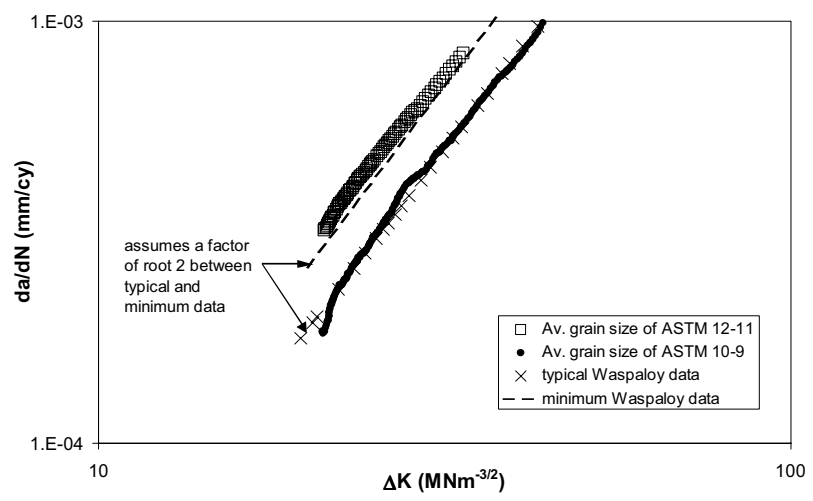

Figure 4. Crack growth rate data at $650^{\circ} \mathrm{C}$ for Alloy \#1 and Waspaloy (grain size of ASTM 8-4) that have been generated at a cyclic frequency of $0.25 \mathrm{~Hz}$ and a stress ratio of 0.1 . The RR1000 data indicate that a relatively small change in average grain size, under creep-fatigue conditions, can result in significant changes in crack growth rate.

Although the rates of crack growth in RR1000 are equivalent to those of coarse grain Waspaloy for material that exhibits an average grain size of ASTM 10-9 (11-16 $\mu \mathrm{m})$, there is limited scope for increasing the average grain size beyond ASTM 12-11 (6-8 $\mu \mathrm{m})$ by applying a near-solvus solution treatment temperature following a sub-solvus forge. This is due to primary $\gamma^{\prime}$, and to a lesser extent MC carbides, that pin grain boundaries at solution treatment temperatures below the $\gamma^{\prime}$ solvus (Figure 5). The required grain size has been achieved via a near-solvus forge and solution treatment, but the process window is considered to be narrow for some complex, large-scale forgings. In such forgings, an average grain size of ASTM 12-11 (6-8 $\mu \mathrm{m})$ is produced consistently by applying the former, more conventional route.

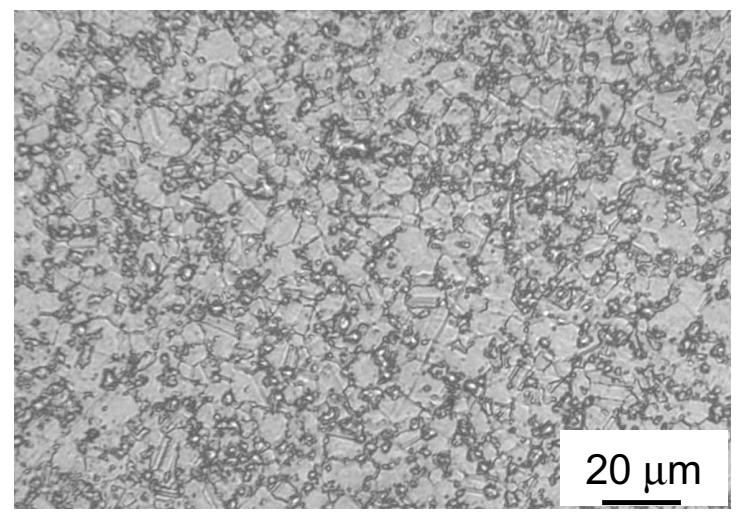

Figure 5(i). Optical micrograph showing the microstructure of Alloy \#2 after near-solvus solution treatment at $1125^{\circ} \mathrm{C}$.

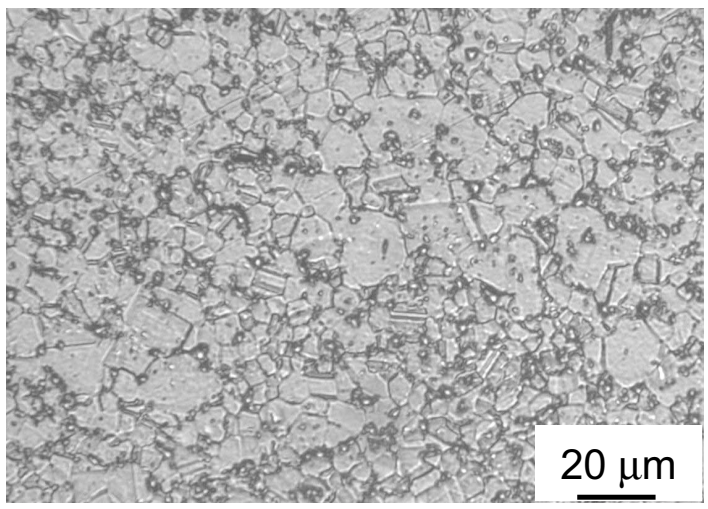

Figure 5(ii) Optical micrograph showing the microstructure of Alloy \#2 after near-solvus solution treatment at $1131^{\circ} \mathrm{C}$. The increase in solution treatment temperature from (i) has reduced the volume fraction of primary $\gamma^{\prime}$ and has increased the As Large As (ALA) grain size but has had a limited effect on the average grain size.

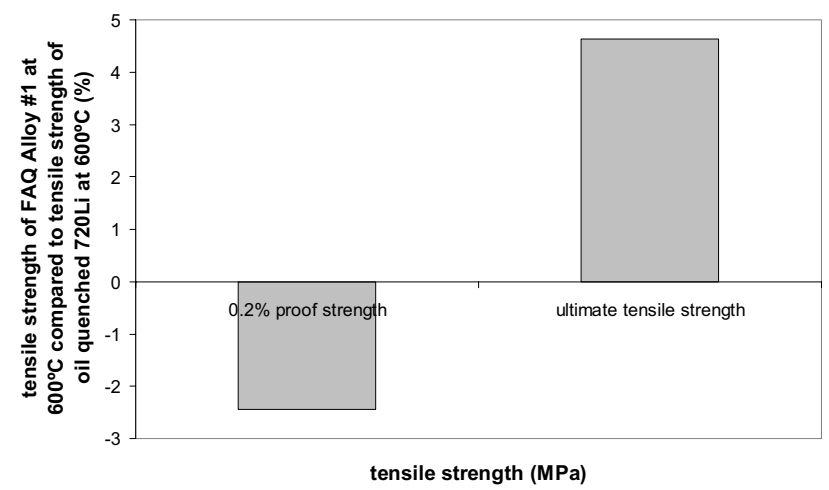

Figure 6. Chart showing the tensile strength of Alloy $\# 1$ at $600^{\circ} \mathrm{C}$. The proof strength is lower than that for oil quenched, cast and wrought $720 \mathrm{Li}$ as fan air quenching (FAQ) was used to cool forged RR1000 material after solution treatment. The RR1000 and $720 \mathrm{Li}$ material showed an average grain size of ASTM 10-9 (11-16 $\mu \mathrm{m})$, ASTM 11-10 $(8-11 \mu \mathrm{m})$ respectively. 
Near-solvus solution treatment, followed by ducted fan aircooling has also delivered the required levels of tensile strength (Figure 6) and creep resistance (Figure 7). Given that fan aircooling generates lower rates of cooling than oil quenching, it is not unexpected that the proof strength of fan air-cooled RR1000 is lower than that for oil quenched $720 \mathrm{Li}$, although $720 \mathrm{Li}$ has a slightly reduced volume fraction of $\gamma^{\prime}$, being $44 \%$ at $725^{\circ} \mathrm{C}$. Further improvements in the strength and creep resistance of RR1000 are now possible, however, as a result of recent developments in processing technology. These are described in a subsequent section.

Unless forgings are for components that are to be joined by inertia welding, RR 1000 is aged at $760^{\circ} \mathrm{C}$ for 16 hours. For welded components, the heat treatments after quenching and welding have been designed to optimise the relief of residual stresses whilst ensuring that the size of tertiary gamma prime ${ }^{25}$, which is produced from the specified ageing heat treatment, is maintained.

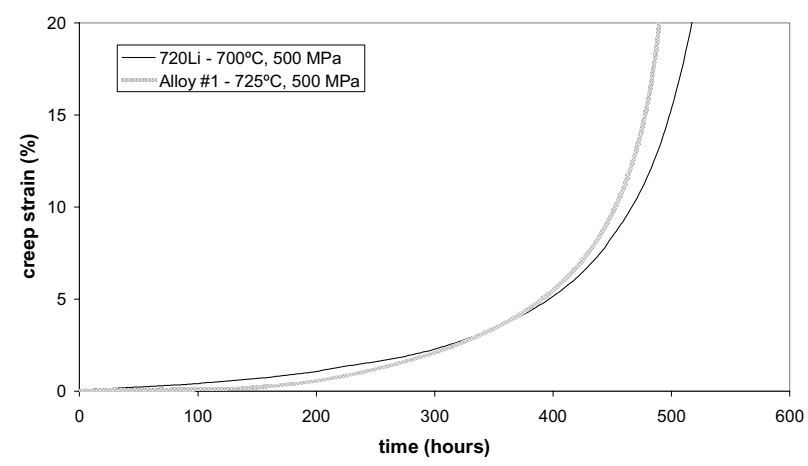

Figure 7. Creep strain data for oil quenched, cast and wrought $720 \mathrm{Li}$ and fan air-cooled RR1000 from a stress of $500 \mathrm{MPa}$. The $\mathrm{RR} 1000$ data were generated at $725^{\circ} \mathrm{C}$, the data for $720 \mathrm{Li}$ at $700^{\circ} \mathrm{C}$. The average grain size for the RR 1000 material was ASTM 12-11 $(6-8 \mu \mathrm{m})$, and ASTM 11-10 $(8-11 \mu \mathrm{m})$ for the $720 \mathrm{Li}$ material.

$\begin{array}{ll}\text { Super Cooler } & A=-473 \\ & \mathrm{~B}=-276 \\ \mathrm{C}=0 \\ \text { Stress }(\mathrm{Mpa})=590 & \mathrm{D}=276 \\ \text { Stress }(\mathrm{Mpa})=-473 & \mathrm{E}=551\end{array}$

Figure 8(i). Predicted values of residual stress for a generic disc forging that is quenched using the Super Cooler.

$\begin{array}{cl}\text { Oil Quench } & \mathrm{A}=-1592 \\ & \mathrm{~B}=-861 \\ & \mathrm{C}=0 \\ \text { Maximum Residual Stress }(\mathrm{Mpa})=1626 & \mathrm{D}=861 \\ \text { Minimum Residual Stress }(\mathrm{Mpa})=-1592 & \mathrm{E}=1626\end{array}$

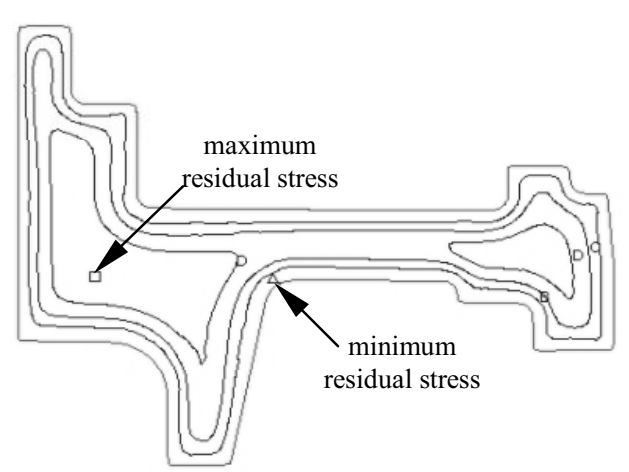

Figure 8(ii). Predicted values of residual stress for a generic disc forging that is quenched by immersion in oil. An identical solution treatment was considered in calculating the predicted values of residual stress that are shown in (i) and (ii).

\section{Recent Developments in Heat Treatment and Quenching of Forgings}

The Super Cooler is a compressed air facility that has been developed by Ladish $^{26}$. Since quenching is achieved by the controlled delivery of compressed air over the surface of the forging, computer-based analytical models can be used to simulate the process. This ability allows the process to be optimised to produce the fastest possible cooling rates throughout the forging and to accommodate differences in section size to minimise cooling rate gradients and hence residual stresses. Results from large development forgings have shown that the use of the Super Cooler has increased the proof strength of RR1000 by $4 \%$ but without the high levels of residual stress that are associated with oil quenching. Figure 8 shows predicted values of residual stress for a generic disc forging that is given an identical solution treatment but which has been quenched using the Super Cooler and by immersion in oil. The residual stresses that result from the Super Cooler are approximately one-third of those that are generated from oil quenching.

Although the data in Figure 3 indicate that solution treatment above the $\gamma^{\prime}$ solvus temperature is unlikely to generate the required strength in the bore/cob of discs, the difference in proof strength between a fine and coarse microstructure becomes less significant at the rim of the forging as the smaller section size enables higher rates of cooling to be achieved throughout the section. At temperatures in excess of $650^{\circ} \mathrm{C}$, at which the rim of discs are required to operate, the difference in ultimate tensile strength between material that exhibits a fine and coarse microstructure becomes insignificant. Furthermore, the ability to 
produce a coarse grain size in the rim can increase the creep resistance of the disc by over $30^{\circ} \mathrm{C}$ (Figure 9) and further improve crack growth resistance, at temperatures at which oxidation and time dependent deformation accelerate crack growth.

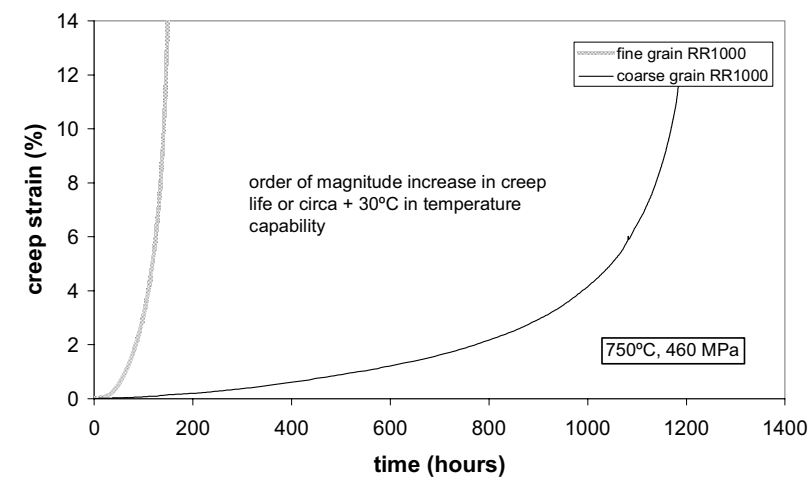

Figure 9. The influence of solution heat treatment temperature on the creep behaviour of Alloy \#1 (in fully heated condition). Fan air-cooling was used to quench forged material after solution treatment.

A complete strain, strain rate and temperature map for RR1000 has been established to predict grain growth and to avoid conditions that may give rise to abnormally large grains during a super-solvus heat treatment. Evidence from a large intermediate pressure (IP) turbine disc forging (Figure 10) has indicated that a coarse grain structure (Figure 11-12) can be produced without critical grain growth.

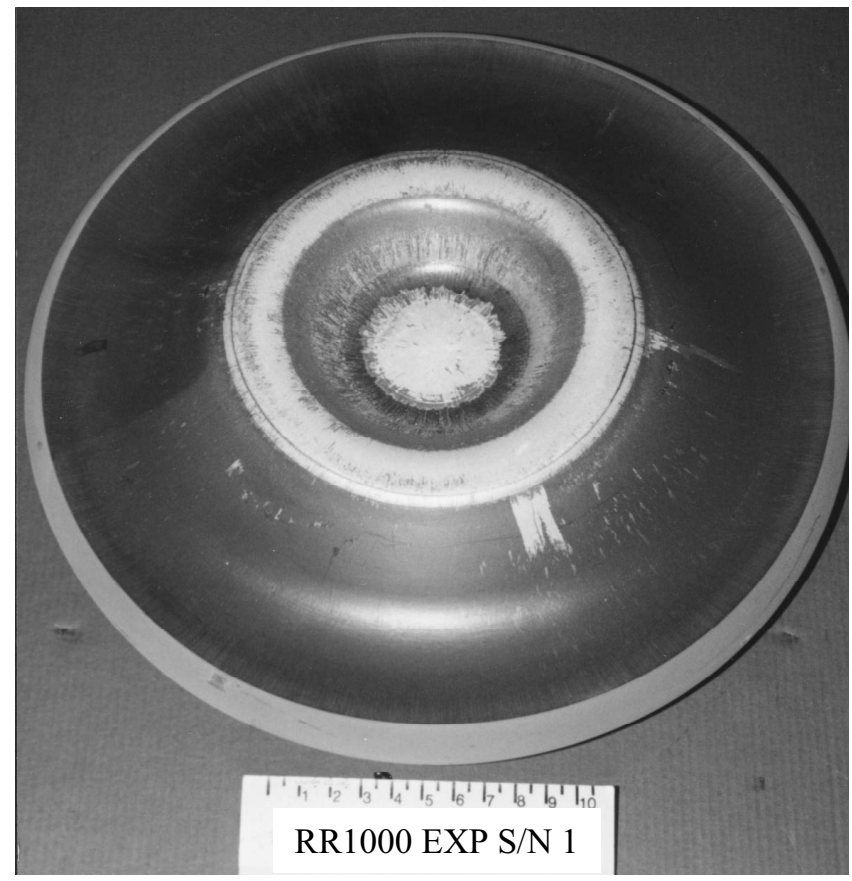

Figure 10. An intermediate pressure (IP) turbine disc forging made from Alloy \#1.

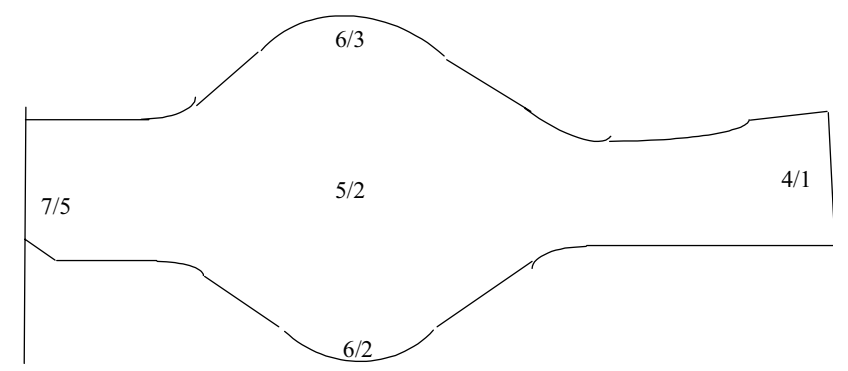

$\mathrm{E}$

Figure 11. Average and As Large As (ALA) grain sizes obtained from a forged and super-solvus heat treated RR1000 IP turbine disc (Figure 10).

Developments in heat treatment technology ${ }^{27}$ to produce dual microstructure forgings are now being validated for production use. These will enable such increases in temperature capability to be realised for alloys that can be super-solvus heat treated to produce a uniform coarse grain size.

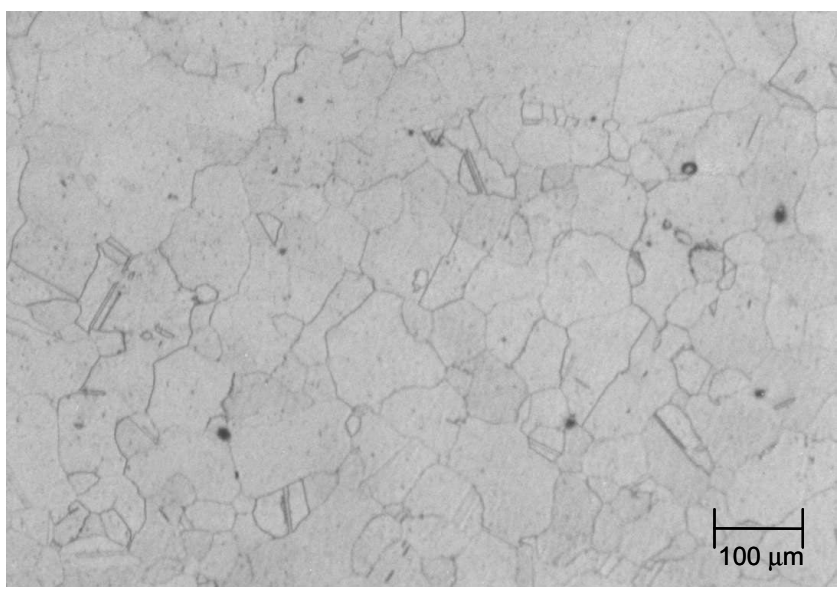

Figure 12. The microstructure of Alloy \#1 after super-solvus solution treatment, and age.

\section{Conclusions}

The composition of RR1000 has been defined so that the minimum volume fraction of $\gamma$ ' achieve the required levels of strength. This approach has been used to encourage damage tolerance. Specific quantities of chromium, cobalt and hafnium, and the ability to decorate grain boundaries with specific amounts of $\mathrm{M}_{23} \mathrm{C}_{6}, \mathrm{M}_{6} \mathrm{C}$ and $\mathrm{MC}$ are considered to be critical in developing good crack growth resistance at elevated temperature, particularly under creep-fatigue conditions. The levels of aluminium, chromium and molybdenum have also been manipulated to avoid excessive TCP formation at the projected time at peak temperature in service. Near-solvus solution heat treatment and fan air-cooling of forged material from consolidated powder billet has established an acceptable balance between tensile strength and crack growth resistance. The resulting fine grain microstructure, coupled with the alloy chemistry, enables a $25^{\circ} \mathrm{C}$ increase in temperature capability over the current disc alloy, $720 \mathrm{Li}$, and an equivalent crack growth resistance to coarse grain Waspaloy. The 
use of an advanced compressed air facility at Ladish has led to a $4 \%$ increase in the proof strength of RR 1000 , and through the development of a coarse microstructure in selected areas of disc forgings, there is an opportunity to increase the temperature capability of the alloy by $30^{\circ} \mathrm{C}$.

\section{Acknowledgements}

The authors would like to thank Rolls-Royce plc and Ladish Co., Inc. for permission to publish this work. Rolls-Royce plc. would like to acknowledge the financial support provided by the UK DTI/MoD, and the technical contributions made by Thermotech Ltd., DERA/QinetiQ, Special Metals Wiggin (Hereford), The University of Cambridge, Special Metals Powder Division (Princeton), Ladish Co., Inc. and Wyman-Gordon Company. The R-R author would like to thank those individuals who have made significant contributions, particularly former colleague Allister James and others including Sarah Franklin, Ian Hussey, Steve Hessell, Colin Small, Wayne Voice, David Bryant and Ken Green of Rolls-Royce plc., Tony Banik of Special Metals Powder Division and Mike Winstone of DSTL.

\section{References}

1. N. Saunders and A.P. Midownik, CALPHAD Calculation of Phase Diagrams - A Comprehensive Guide (Pergammon, Oxford, UK, 1998).

2. N. Saunders, "Phase Diagram Calculations for Ni-Based Superalloys", Superalloys 1996, ed. R.D. Kissinger, D.J. Deye, D.L. Anton, A.D. Cetel, M.V. Nathal, T.M. Pollock, and D.A. Woodford (Warrendale, PA, USA: The Minerals, Metals and Materials Society, 1996), 101-110.

3. D.W. Hunt, "The Stability and Mechanical Properties of a Nickel-Base Turbine Disc Alloy" (PhD Thesis, Emmanuel College, University of Cambridge, UK, 2001).

4. N. Saunders, M. Fahrman, and C.J. Small, "The Application of CALPHAD Calculations to Ni-Based Superalloys", Superalloys 2000, ed. T.M. Pollock, R.D. Kissinger, R.R. Bowman, K.A. Green, M. McLean, S.L. Olson and J.J. Schirra, (Warrendale, PA, USA: The Mineral, Metals and Materials Society, 2000), $803-811$.

5. W.J. Boesch and J.S. Slaney, "Preventing Sigma Phase Embrittlement in Nickel Base Superalloys", Metal Progress, 86, (1964), 109-111.

6. D.W. Hunt et al., "Microstructural Stability and Crack Growth Behaviour of a Polycrystalline Nickel-Base Superalloy", Superalloys 2000, ed. T.M. Pollock, R.D. Kissinger, R.R. Bowman, K.A. Green, M. McLean, S. Olson and J.J. Schirra, (Warrendale, PA, USA: The Minerals, Metals and Materials Society, 2000), 795-802.

7. S.J. Hessell, W. Voice, A.W. James, S.A. Blackham, C.J. Small, and M.R. Winstone, "Nickel Alloy for Turbine Engine Components", (US Patent 6,132,527, 2000).
8. N.S. Stoloff, "Fundamental of Strengthening", Superalloys II, ed. C.T. Sims, N.S. Stoloff and W.C. Hagel (John Wiley \& Sons, New York, USA, 1987), 61-96.

9. A.K. Jena and M.C. Chaturvedi, "The Role of Alloying Elements in the Design of Nickel-Base Superalloys", J.Mat. Sci., 19, (1984), 3121-3139.

10. P.A.S. Reed and J.E. King, "Comparison of Long and Short Crack Growth in Polycrystalline and Single Crystal Forms of Udimet 720", Short Fatigue Cracks, ed. K.J. Miller and E.R. de los Rios (Mechanical Engineering Publications, London, UK, 1992), 153-168.

11. P.W. Keefe, S.O. Mancuso, and G.E. Maurer, "Effects of Heat Treatment and Chemistry on the Long-Term Phase Stability of a High Strength Nickel-Based Superalloy, Superalloys 1992, ed. S.D. Antolovich, R.W. Stusrud, R.A. MacKay, D.L. Anton, T. Khan, R.D. Kissinger, and D.L. Klarstrom (Warrendale, PA, USA: The Mineral, Metals and Materials Society, 1992), $487-496$.

12. S. Floreen, Mechanical Behavior, "Mechanical Behavior", Superalloys II, ed. C.T. Sims, N.S. Stoloff and W.C. Hagel (John Wiley \& Sons, New York, USA, 1987), 241-262.

13. C.T. Sims, "Prediction of Phase Composition", Superalloys II, ed. C.T. Sims, N.S. Stoloff and W.C. Hagel (John Wiley \& Sons, New York, USA, 1987), 217-240.

14. H.Y.Li and P. Bowen, "Effect of Hafnium on the CreepFatigue Crack Growth resistance of Nickel Based Superalloy RR1000 at $725^{\circ} \mathrm{C}$ " (Technical Report from the University of Birmingham, UK, 2000).

15. D.J. Bryant and G. McIntosh, "The Manufacture and Evaluation of a Large Turbine Disc in Cast and Wrought Alloy 720Li”, Superalloys 1996, ed. R.D. Kissinger, D.J. Deye, D.L. Anton, A.D. Cetel, M.V. Nathal, T.M. Pollock, and D.A. Woodford (Warrendale, Pennsylvania, USA: The Minerals, Metals and Materials Society, 1996), 713-722.

16. J.C. Lautridou, J.Y. Guedou and Y. Honnorat, "Effect of Inclusions on LCF life of PM Superalloys for Turboengine Discs", High Temperature Materials for Power Engineering, ed. E. Bachelet et al, (London, UK: Kluwer Academic Publishers, 1990), 1163-1172.

17. E.S. Huron and P.G. Roth, "The Influence of Inclusions on Low Cycle Fatigue Life in a P/M Nickel-Base Disk Superalloy", Superalloys 1996, ed. R.D Kissinger, D.J. Deye, D.L. Anton, A.D. Cetel, M.V. Nathal, T.M. Pollock, and D.A. Woodford (Warrendale, Pennsylvania, USA: The Minerals, Metals and Materials Society, 1996), 359-368.

18. G.A. Miller, K.A. Green, A. Banik, J. Lemsky and G.Y. Richardson, "Enhanced Powder Metallurgy (P/M) Processing of Udimet 720 AE1107C (T406) Turbine Disks", Advanced Technologies for Superalloy Affordability, ed. K.-M. Chang, S.K. Srivastava, D.U. Furrer, and K.R. Bain (Warrendale, Pennsylvania, USA: The Minerals, Metals and Materials Society, 2000), 37-48. 
19. X. Pierron, A. Banik, G.E. Maurer, J. Lemsky, D.U. Furrer and S. Jain, "Sub-Solidus HIP Process for P/M Superalloy Conventional Billet Conversion" Superalloys 2000, ed. T.M. Pollock, R.D. Kissinger, R.R. Bowman, K.A. Green, M. McLean, S. Olson and J.J. Schirra, (Warrendale, Pennsylvania, USA: The Minerals, Metals and Materials Society, 2000), 425-433.

20. A. Banik, K.A. Green, D.P Mourer and T. Reay, "Low Cost Powder Metal Turbine Components", (Paper presented at the $10^{\text {th }}$ International Symposium on Superalloys, Seven Springs Mountain Resort, Champion, PA, 19-23 September 2004).

21. G.Shen and D. Furrer, "Manufacturing of Aerospace Forgings", Journal of Materials Processing Technology, 98, 2000, 189-195.

22. Pineau, "High Temperature Fatigue of Ni-Base Superalloys: Microstructural and Environmental Effects", Engineering Against Fatigue, ed. J.H. Beynon, M.W. Brown, R.A. Smith, T.C. Lindley and B. Tomkins (A.A. Balkema, Rotterdam, Netherlands, 1999), 557-565.

23. Unpublished R-R work.

24. I.M. Wilcock, D.G Cole, J.W. Brooks, and M.C. Hardy, "Creep/fatigue behaviour of P/M nickel disc alloys", Parsons 2003 - Engineering Issues in Turbine Machinery, Power Plant and Renewables, ed. A. Strang, R.D. Conroy, W.M. Banks, M. Blackler, J. Leggett, G.M. McColvin, S. Simpson, M. Smith, F. Starr and R.W. Vanstone (Institute of Materials, Minerals and Mining, London, UK, 2003), 749-764.

25. M. Preuss, J.W.L. Pang, P.J. Withers, and G.J. Baxter, "Inertia Welding Nickel-Based Superalloy: Part I. Metallurgical Characterization", Met. Trans., 33A, October 2002, 3215-3225.

26. G. Bunge, D. Furrer, R. Shanker and C. White, "Super Cool Technology for Improved Heat Treatment", Materials World, May 2003, 10-12.

27. J. Gayda and D. Furrer, "Dual-Microstructure Heat Treatment", Advanced Materials and Processes, July 2003, 36-39. 